Article

\title{
Prediction of Polymer Flooding Performance with an Artificial Neural Network: A Two-Polymer-Slug Case
}

\author{
Jestril Ebaga-Ololo $\mathbb{D}$ and Bo Hyun Chon * \\ Department of Energy Resources Engineering, Inha University, Incheon 402-751, Korea; \\ jestril.ebagaololo@inha.edu \\ * Correspondence: bochon@inha.ac.kr; Tel.: +82-32-860-7556 \\ Academic Editor: Vijay Kumar Thakur \\ Received: 31 May 2017; Accepted: 21 June 2017; Published: 1 July 2017
}

\begin{abstract}
Many previous contributions to methods of forecasting the performance of polymer flooding using artificial neural networks (ANNs) have been made by numerous researchers previously. In most of those forecasting cases, only a single polymer slug was employed to meet the objective of the study. The intent of this manuscript is to propose an efficient recovery factor prediction tool at different injection stages of two polymer slugs during polymer flooding using an ANN. In this regard, a back-propagation algorithm was coupled with six input parameters to predict three output parameters via a hidden layer composed of 10 neurons. Evaluation of the ANN model performance was made with multiple linear regression. With an acceptable correlation coefficient, the proposed ANN tool was able to predict the recovery factor with errors of $<1 \%$. In addition, to understand the influence of each parameter on the output parameters, a sensitivity analysis was applied to the input parameters. The results showed less impact from the second polymer concentration, owing to changes in permeability after the injection of the first polymer slug.
\end{abstract}

Keywords: artificial neural network; enhanced oil recovery; polymer flooding; polymer slugs

\section{Introduction}

With ever-increasing energy consumption demand and a declining trend in the discovery of significant new oil fields, redevelopment of mature oil wells has gained great attention in the oil and gas industry. It is estimated that two-thirds of the oil originally in place are left after the primary and secondary recovery stages [1]. This remaining amount of oil has focused the attention of industries and researchers on developing new techniques referred to as tertiary oil recovery methods [2]. These techniques can be classified into three distinct methods: miscible oil recovery, thermal oil recovery, and chemical oil recovery.

Chemical oil recovery is applied to reservoirs as a tertiary method when waterflooding has reached its recovery efficiency limit, which is estimated to be approximately $30-50 \%$ of the original oil in place (OOIP) [3,4]. It is an effective method to recover the residual oil trapped by capillary forces after waterflooding. To do so, chemical materials are injected into the reservoirs to change the wettability of the fluids, increase the sweep efficiency, or decrease the interfacial tension between water and oil. Three essential processes are related to it: surfactant flooding, alkaline flooding, and polymer flooding.

With more than four decades of application in different oil wells [5], polymer flooding, according to Sheng and Alsofi, is a mature technology and the most applied chemical flooding method, with significant successes mainly in China where it has become the main technique applied to recover oil from the Daqinq and Shengli oilfields [6-8]. Basically, injecting a polymer can reduce the mobility ratio of the aqueous phase between oil and water, leading to a smooth movement of oil toward the producing well(s) by increasing the viscosity of the injected water and reducing the permeability of 
the aqueous phase. However, the recovery of incremental oil compared to waterflooding represents an economic incentive for applying polymer flooding. Recovering oil using this method is a challenging task if the water-to-polymer mobility ratio is unfavorable. To avoid such a situation, assessment of the performance of polymer flooding must be conducted to predict the recovery factor or cumulative production resulting from the operation.

Conventional methods have been used to evaluate the performance of polymer flooding by predicting the recovery factor and/or the cumulative production, the bearing on enhanced oil recovery's (EOR) efficiency on the effects of capillary pressure, polymer on viscosity, interfacial tensions, and the wave structures associated in two space dimensions resulting in fingering; these include the use of reservoir numerical simulations [9-11] fractional flow theory [12,13], and mathematical methods [14,15]. These methods have numerous drawbacks, such as the requirement of a substantial amount of data related to the geology and geometry of the reservoir, or the fluids and rock properties. The processing of this data is a time-consuming operation, resulting in inaccurate results owing to multiple errors. Developing a simple, fast, and accurate prediction tool to evaluate polymer flooding performance is strongly needed.

There are numerous studies available in the literature where artificial neural networks workflow has been developed to tackle problems of different nature in petroleum engineering. Based on the ability of ANNs in solving identification problems, Masoudi et al. [16] were able to determine the net pay zones of two reservoirs, a carbonate reservoir of Mishrif and a sandy reservoir of Burgan in Iran, obtaining a classification correctness rate $>85 \%$. Despite the large abundance of wireline logs in most drilled oilfield wells, the core data essential to the determination of water saturation are only available in few wells. Because of that lack, Al-Bulushi et al. [17] designed an ANN which with a $\mathrm{R}^{2}$ of 0.91 and a root mean square error (RMSE) of 2.5 was able to predict water saturation by later applying sensitivity analyses to confirm the robustness of the model used. ANNs have also been applied in prediction of oil recovery factors and cumulative oil production. By using higher-order neural networks (HONNs), Chithra Chakra et al. [18] were able to predict petroleum oil production without requiring sufficient training data. Mohammadi et al. [19] however put the emphasis of their studies on the prediction of oil recovery factors in $\mathrm{CO}_{2}$ injection. The result was mainly appreciable regarding the RMSE, which was evaluated to be $0.396 \%$. For EOR processes and especially chemical enhanced oil recovery (CEOR), a number of studies have been dedicated to the utilization of ANN. By applying ANN to the viscosity estimator of Flopaam $^{\text {TM } 3330 S \text {, Flopaam }}{ }^{\text {TM }} 3630$ S and AN-125, Kang et al. [20] came to the conclusion that ANN model has higher polymer viscosity prediction accuracy compared to the conventional prediction model known as the Carreau model. Al-Dousari et al. predicted the recovery factor of surfactant polymer flooding. In the first case, the prediction was made at three different pore volumes $(0.75,1.5,2.25)$ by applying a blind-test on 125 data sets, which gave an average absolute error of $3 \%$ [21].

In this study, we predicted the recovery factor (RF) during polymer flooding using a neural network at three different periods: after waterflooding $\left(\mathrm{RF}_{1}\right)$, after the injection of the first polymer slug $\left(\mathrm{RF}_{2}\right)$, and after the injection of the second polymer slug $\left(\mathrm{RF}_{3}\right)$. The results of this study can serve as an example to show the capacity of an ANN in predicting the performance of the injection of two or more polymer slugs during polymer flooding. Furthermore, a sensitivity analysis can be applied to the input parameters for finding the best-performing parameters to maximize the recovery factor.

\section{Methodology}

\subsection{Data Gathering and Polymer Flooding Simulation}

Reservoir data and polymer concentrations were gathered from previous attempted studies in which polymer flooding had been simulated $[10,22]$. Reservoir simulations coupled with polymer concentrations were conducted to obtain a bank of polymer flooding data.

The study consisted of a sandstone reservoir with a five-spot well pattern composed of four producer wells and one injector well discretized into $30 \times 30 \times 5$ grid blocks. The producer wells were located 
$1450 \mathrm{ft}$ from each other and $1025.3 \mathrm{ft}$ away from the injector well as sketched in Figure 1, with all wells designed using CMG's STARS simulator (Computer Modeling Group Ltd, Calgary, AB, Canada).

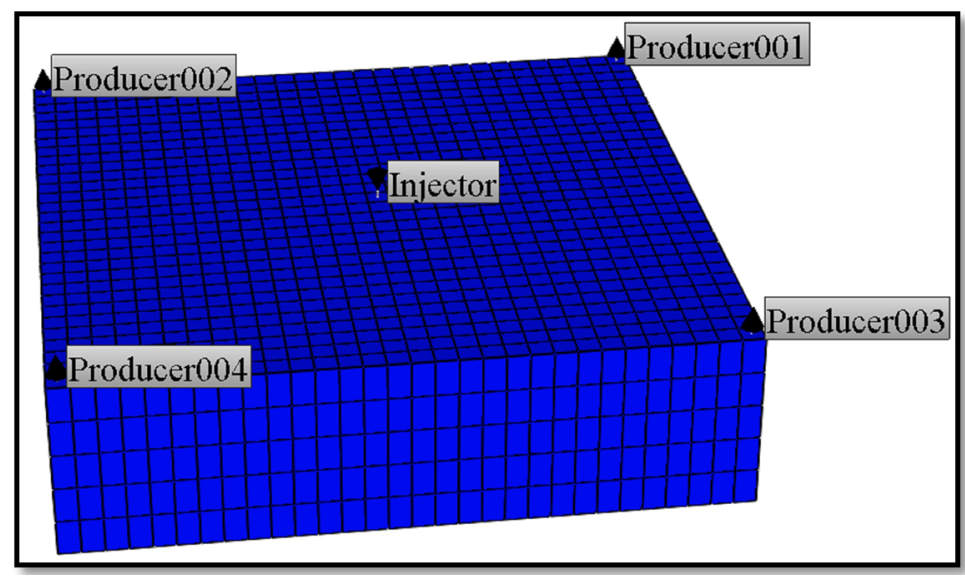

Figure 1. Representation of the five-spot well pattern reservoir model.

As depicted in Table 1, the permeability and porosity over the five layers were assumed to be constant with initial oil saturation $\left(S_{o i}\right)$ and viscosity $(\mu)$ estimated to be, respectively, 0.75 and $20 \mathrm{cp}$.

Table 1. Description of the reservoir properties.

\begin{tabular}{cc}
\hline \multicolumn{2}{c}{ Reservoir Properties } \\
\hline System dimensions of one cell $\left(\mathrm{ft}^{3}\right)$ & $50 \times 50 \times 4$ \\
Formation depth $(\mathrm{ft})$ & 4985 \\
Formation temperature $\left({ }^{\circ} \mathrm{F}\right)$ & 148 \\
Initial oil saturation & 0.75 \\
Connate water & 0.25 \\
Residual oil to saturation & 0.22 \\
Porosity $(\%)$ & 30 \\
Oil viscosity $(\mathrm{cp})$ & 20 \\
Absolute permeability (darcy) & 1 \\
$K_{\text {ro }}$ at connate water & 0.9 \\
$K_{\text {rw }}$ at residual oil & 0.3 \\
\hline
\end{tabular}

The uniformity of the five layers in terms of porosity and permeability were set up to allow better flooding performance. According to the in situ oil viscosity and reservoir temperature from Table 1, for an effective viscosity ratio to sweep oil during polymer flooding, the viscosity of Polymer Slug 1 should be at least $20 \mathrm{cp}$. Therefore, a range of polymer viscosities were chosen, with the lowest value being $10.8 \mathrm{cp}$, as listed in Table 2 .

Table 2. Polymer viscosity and polymer concentration parameters.

\begin{tabular}{cc}
\hline Viscosity (cp) & Concentration (wt.\%) \\
\hline 10.8 & 0.1503 \\
13 & 0.16 \\
18 & 0.1802 \\
21.7 & 0.2427 \\
29.1 & 0.3413 \\
38.2 & 0.4048 \\
38.3 & 0.4055 \\
51.8 & 0.499 \\
76 & 0.5644 \\
\hline
\end{tabular}


During polymer flooding, the injected polymer after a certain time contributed to the changes in the viscosity of the injected water. The water phase viscosity $\left(\mu_{p}\right)$ in centipoise is then a function of polymer concentration $\left(c_{p}\right)$ in weight percent and can be determined using the following equation:

$$
u_{p}=\mu_{w}\left(1+10 c_{p}+10^{2} c_{p}^{2}+10^{3} c_{p}^{3}\right),
$$

where $\mu_{w}=1 \mathrm{cp}$ is water viscosity [23]. Based on the new water viscosity estimated by using Equation (1), the chosen polymer viscosity as shown previously in Table 2 could thus be confirmed by determining their mobility ratio as proceeded in Table 3.

Table 3. Mobility ratio determination based on water viscosity as a function of polymer concentration.

\begin{tabular}{cccc}
\hline Viscosity (cp) & Concentration (wt.\%) & Water Viscosity (cp) & $\boldsymbol{M}$ \\
\hline 10.8 & 0.1503 & 8.157 & 0.817 \\
13 & 0.16 & 9.256 & 0.720 \\
18 & 0.1802 & 11.901 & 0.560 \\
21.7 & 0.2427 & 23.613 & 0.282 \\
29.1 & 0.3413 & 55.818 & 0.119 \\
38.2 & 0.4048 & 87.766 & 0.076 \\
38.3 & 0.4055 & 88.174 & 0.076 \\
51.8 & 0.499 & 155.142 & 0.043 \\
76 & 0.5644 & 218.287 & 0.031 \\
\hline
\end{tabular}

$M$ pertains to the mobility ratio and can be calculated using:

$$
M=\frac{\frac{K_{r v}}{\mu_{p}}}{\frac{K_{r o}}{\mu_{o}}},
$$

where $K_{r w}=0.3$ and $K_{r o}=0.9$ are respectively the water relative permeability and the oil relative permeability as shown in Figure 2, $\mu_{p}$ the calculated water viscosity based on Equation (1), and finally $\mu_{o}=20 \mathrm{cp}$ the oil viscosity. During polymer flooding, floods presenting a mobility ratio $<1$ are considered as stable, thus leading to better recovery, while on the other hands floods with a mobility ratio $>1$ are considered as unstable [24].

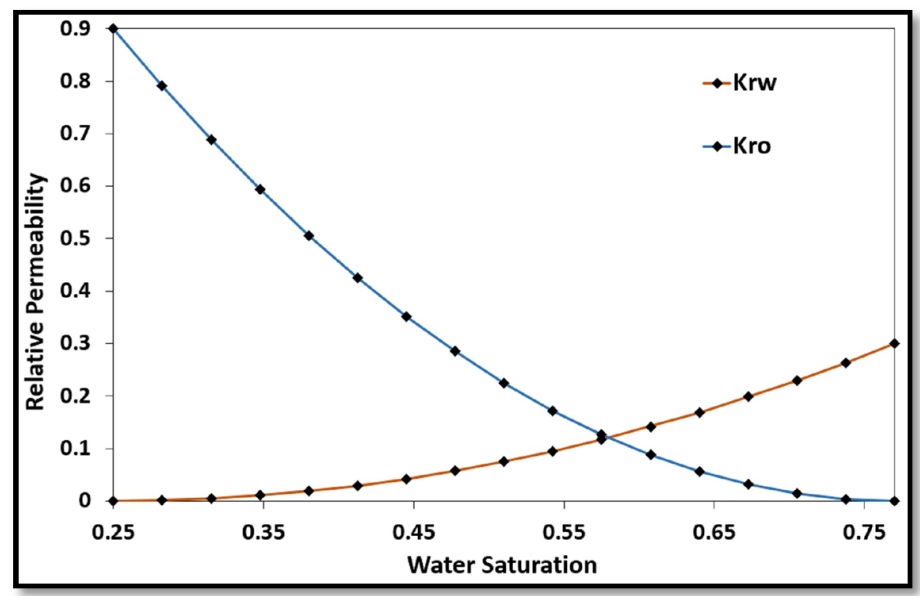

Figure 2. Relative permeability profile at the before the injection of polymer flooding.

The reservoir was then subjected to simulated polymer flooding. The simulation consisted of running 25 distinct cases separately for a certain period of time from 30 to 72 months, as listed in Table 4 . 
Table 4. Range of variables in the dataset.

\begin{tabular}{cccccc}
\hline Parameters & Unit & Type & Minimum & Average & Maximum \\
\hline Polymer Slug Size 1 (A) & month & Input & 12 & 24 & 36 \\
Drive Water Slug Size (B) & month & Input & 9 & 13 & 18 \\
Polymer Slug Size 2 (C) & month & Input & 9 & 13 & 18 \\
Concentration of Polymer Slug Size 1 $\left(\mathrm{P}_{1}\right)$ & wt.\% & Input & 0.2427 & 0.4033 & 0.5644 \\
Concentration of Polymer Slug Size 2 $\left(\mathrm{P}_{2}\right)$ & $\mathrm{wt.} \%$ & Input & 0.1503 & 0.3581 & 0.5644 \\
Injection Rate (Q) & $\mathrm{bbl}$ & Input & 5000 & 6000 & 7000 \\
Recovery Factor 1 $\left(\mathrm{RF}_{1}\right)$ & $\%$ & Output & 5.146853 & 7.346445 & 9.713352 \\
Recovery Factor 2 $\left(\mathrm{RF}_{2}\right)$ & $\%$ & Output & 10.15411 & 15.65818 & 26.94706 \\
Recovery Factor 3 $\left(\mathrm{RF}_{3}\right)$ & $\%$ & Output & 15.03236 & 25.319596 & 43.2764 \\
\hline
\end{tabular}

The cases studies were selected randomly from among a thousand possibilities based on the characteristics of four out of six parameters screened, namely, A, B, C, P1, P2, and Q. To enhance the first injection of the polymer, a pre-flush operation was completed for a period of six months following the recommendation available in the literature for a successful pre-flush period to meet a water cut not being $\leq 92 \%$ [6]. In addition, to avoid obtaining a uniform polymer slug, the water drive slug (B) was implemented for a period between nine and 18 months with the first polymer being injected for a maximum time of 36 months and a minimum time of 12 months. The second polymer, however, was injected for a shorter time (between nine and 18 months) and was also followed by a post-flush period fixed to 18 months. The time between the different operations was crucial for successful implementation of the two slugs. The two polymers had different concentrations.

After the results of the 25 cases were obtained, an extensive simulation was completed under CMOST of CMG, focusing on concentration alteration. $\mathrm{P}_{1}$ and $\mathrm{P}_{2}$ were fluctuated from their lowest values to their highest values and so forth. For each simulation result obtained using STARS, 15 extensive results were obtained with distinct outcomes under CMOST. A set of 400 simulations results were thus obtained for testing with the ANN process.

\subsection{ANN Structure and Model}

The use of ANNs in the petroleum industry has gained considerable interest for its usefulness in correlating specific solutions based on the broad range of data used. ANNs do not rely on mathematical equations or a pre-prepared program to estimate accurate solutions. Instead, ANNs process information by miming the procedure used by the human brain, which consists of learning the relationship between the data gathered and the data obtained. This is a complicated nonlinear task completed throughout a network composed of numerous layers, which include input layers, output layers, and hidden layers.

The designed ANN feed-forward back-propagation model applied has been demonstrated to be an effective learning schemer. The back-propagation algorithm is considered as the most widely used algorithm [17]. Associated with the feed-forward ANN architecture, this consists of propagating a signal from input to output, and updating the whole cycle retrospectively after obtaining the error value resulting in the comparison of the calculated value(s) to the real value(s). This process can be completed in three steps. The first step, or the feed-forward computation, consists of obtaining the value(s) of the hidden layers through pushing the input value into the hidden layer node by multiplying the weight connecting the node. Once obtained, the hidden layer value is computed through the sigmoid function to obtain the output value using the following equation:

$$
f(x)=\frac{1.0}{1.0+e^{-x}}
$$

The backward propagation, or the second step, is a two level computation. The first level is the propagation to the output layers, which consists of obtaining the error value between the calculated value and real value. Once known, it is sent backwards to adjust or update the weight. This is then 
followed by the final step, or the backward propagation of the hidden layer. The product of the new weight and the error rate at the output will give the error rate at the hidden node. Once obtained, the error rate between hidden node and input node will be evaluated as well, and the cycle will proceed so forth from the first input to the last one.

Six input parameters were used in the input layers: polymer slug size $1(\mathrm{~A})$, drive water slug size (B), polymer slug size $2(\mathrm{C})$, concentration of polymer slug size $1\left(\mathrm{P}_{1}\right)$, concentration of polymer slug size $2\left(\mathrm{P}_{2}\right)$, and injection rate $(\mathrm{Q})$. The recovery factor was the main parameter in the output layer and was divided into three distinct phases: recovery factor $1\left(R_{1}\right)$, recovery factor $2\left(R_{2}\right)$, and recovery factor $3\left(\mathrm{RF}_{3}\right)$. The hidden layer, however, was composed of 10 neurons. Figure 3 depicts the architecture of the ANN model.

The generated data from the simulation results were used to model the ANN network under a MATLAB environment. The database was divided into three distinct parts for training (180), validating (80), and testing (140) purposes, based on the ratios 45:20:35. The training and testing processes were allocated the greatest size. These particular allocations were chosen to best appraise and confirm the general performance of the ANN and to obtain a higher degree of confidence in the obtained results [25].

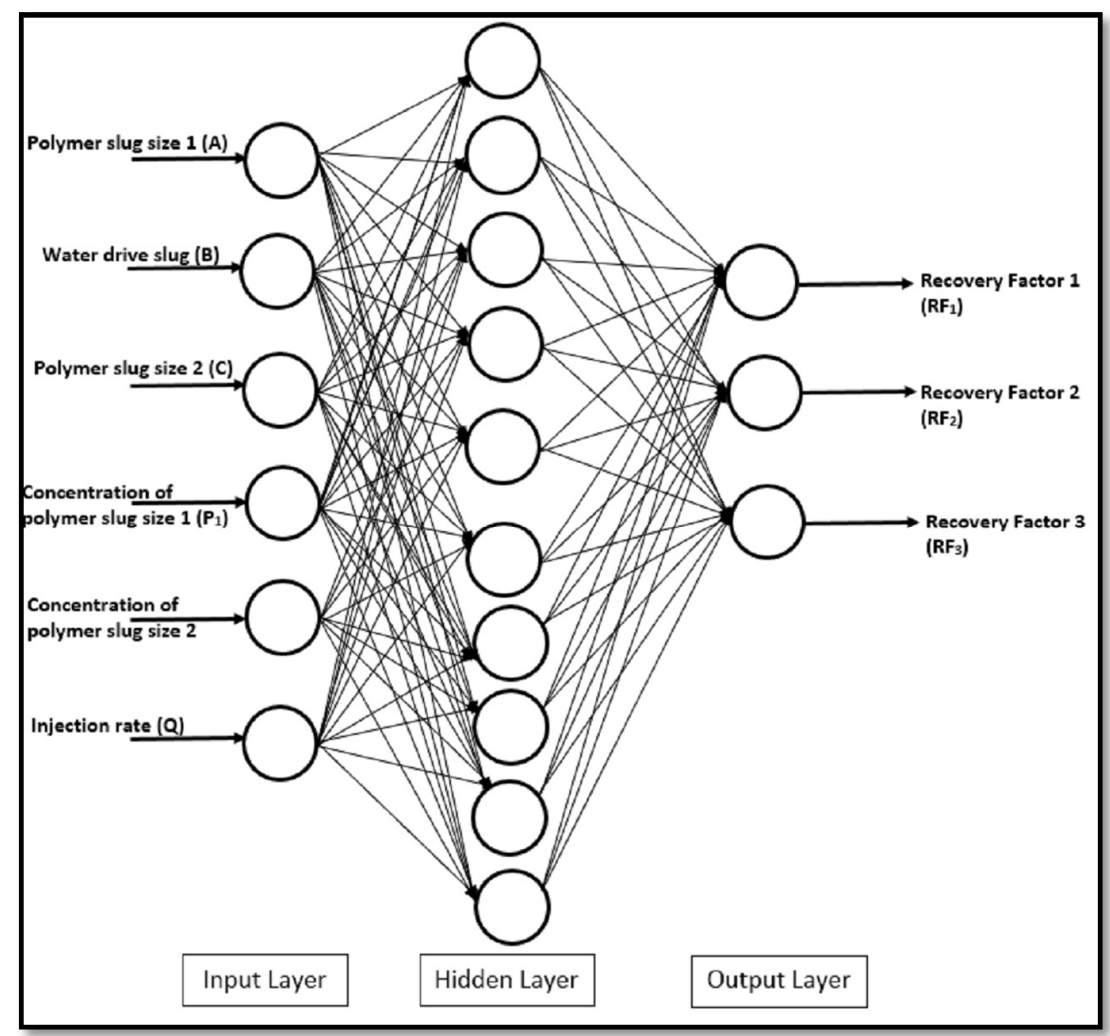

Figure 3. Architecture of the artificial neural network (ANN) model composed of six input variables, 10 hidden layers, and three output variables.

To reduce data redundancy, avoid the effects of magnitude differences, and improve the integrity of the training performance of the ANN model, the simulated data were normalized. Ahmadloo et al. [26] define data normalization as the process of standardizing the possible range of the input data. In our study, the possible range was set by constant values falling between 0.1 and 1.1 obtained after calculation using:

$$
X_{n}=\frac{X_{s}-X_{\min }}{X_{\max }-X_{\min }}+0.1
$$

where $X_{n}, X_{s}, X_{\min }$, and $X_{\max }$ are, respectively, the normalized value, the value obtained from simulation, the minimum value, and the maximum value. To assess the fitness and prediction accuracy 
of the results obtained, two statistical parameters were considered: the root mean square error (RMSE) and the correlation coefficient $\left(R^{2}\right)$. Their values were obtained using:

$$
\begin{aligned}
\text { RMSE } & =\sqrt{\frac{1}{N} \sum\left(X_{s}-X_{p}\right)^{2}} \\
\text { and } \mathrm{R}^{2} & =1-\sum \frac{\left(X_{s}-X_{p}\right)^{2}}{\left(X_{s}-\overline{X_{s}}\right)^{2}}
\end{aligned}
$$

where the parameters $N, X_{p}, X_{s}$, and $\overline{X_{s}}$ are, respectively, the number of parameters, the predicted value obtained by the $\mathrm{ANN}$, the simulated value, and the average simulated value.

\section{Results and Discussion}

The simulated recovery factor data obtained from STARS were used to develop the neural network model. In total, 400 data points were used for this process, and these were divided into three distinct categories based on the ratios 45:20:35. The Levenberg-Marquardt back-propagation algorithm function (trainlm) was used for training the proposed network to generate a network that had the capability to generalize accurately and perform a prediction with approximately no errors.

Figure 4 shows the simulated data against the predicted data obtained during the training process by the $\mathrm{ANN}$ for $\mathrm{RF}_{1}, \mathrm{RF}_{2}$, and $\mathrm{RF}_{3}$. It illustrates an almost perfect linear fit. This assumption was confirmed by a correlation coefficient with an overall value of 0.999 for the recovery factor.

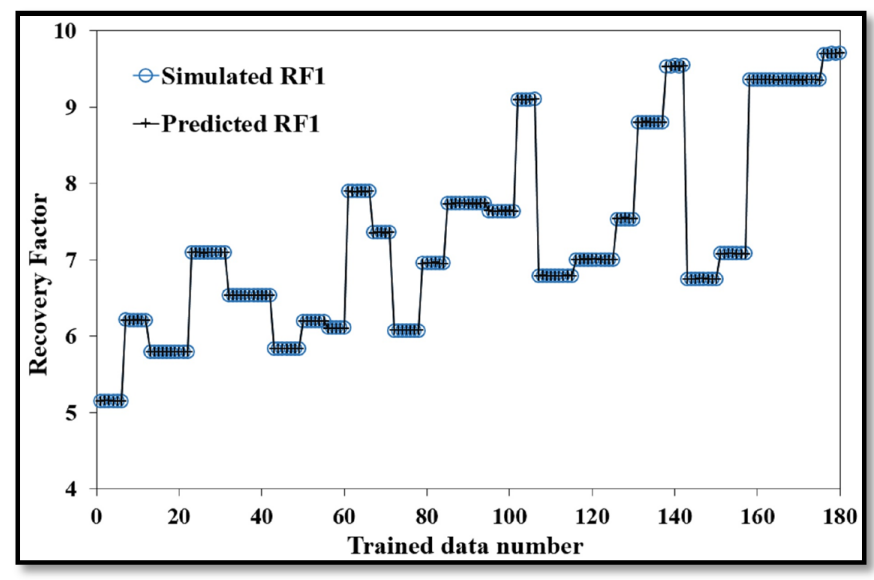

(a)

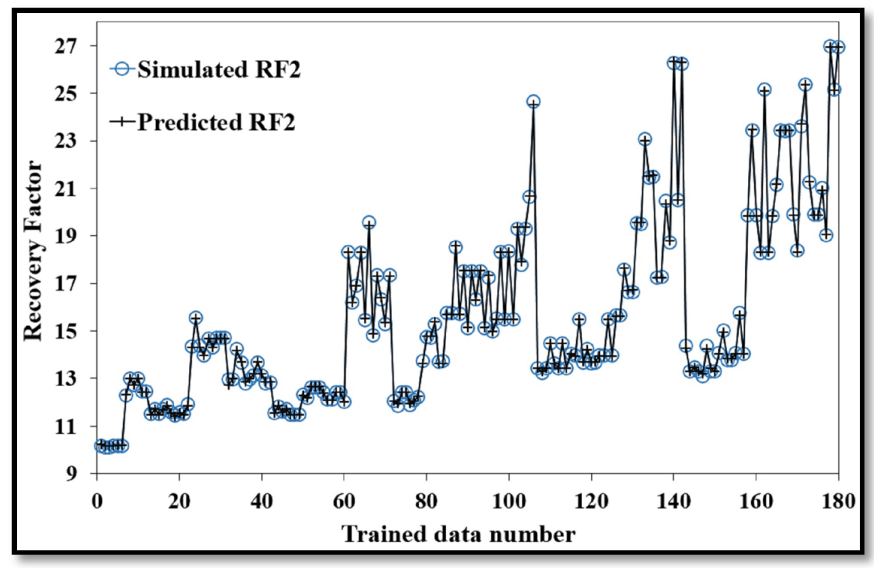

(b)

Figure 4. Cont. 


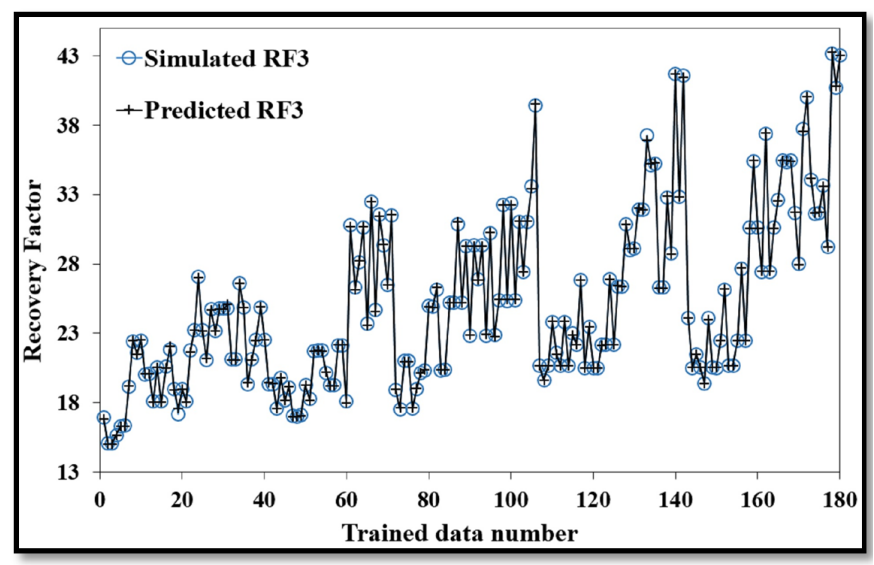

(c)

Figure 4. Comparison between simulated and predicted $R F$ values in the training process for $(a) R_{1}$, (b) $\mathrm{RF}_{2}$, and (c) $\mathrm{RF}_{3}$.

The strong correlation between the simulated and predicted data is shown in Figure 5.

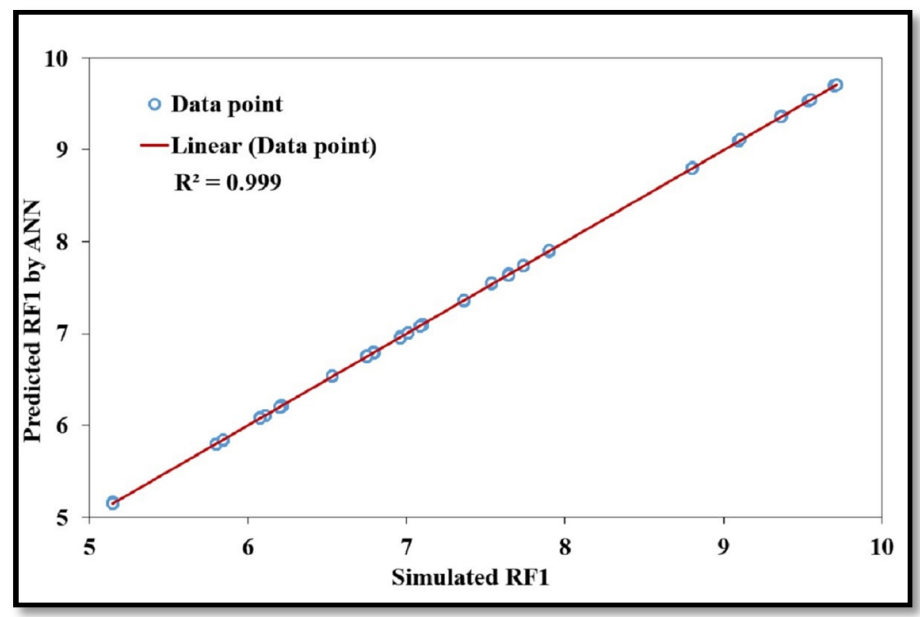

(a)

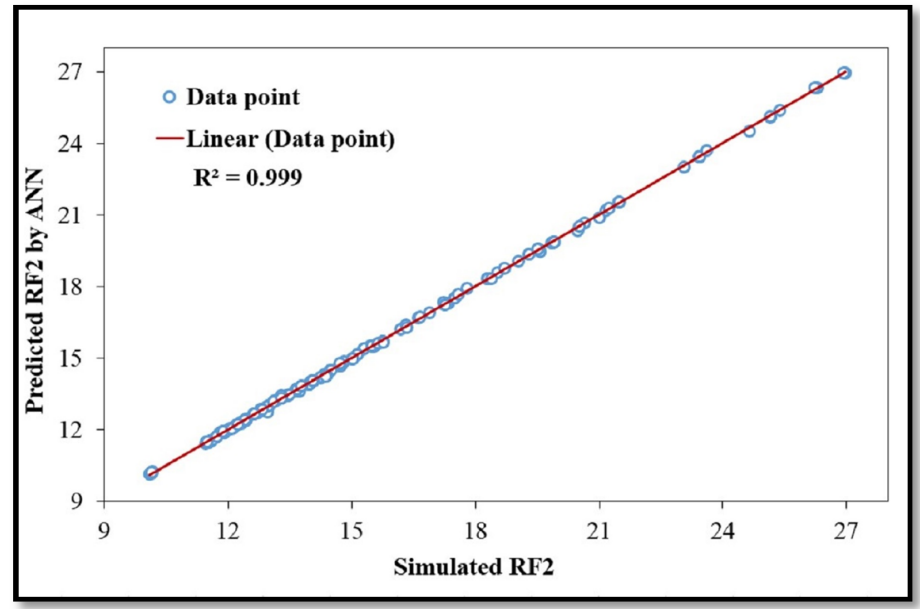

(b)

Figure 5. Cont. 


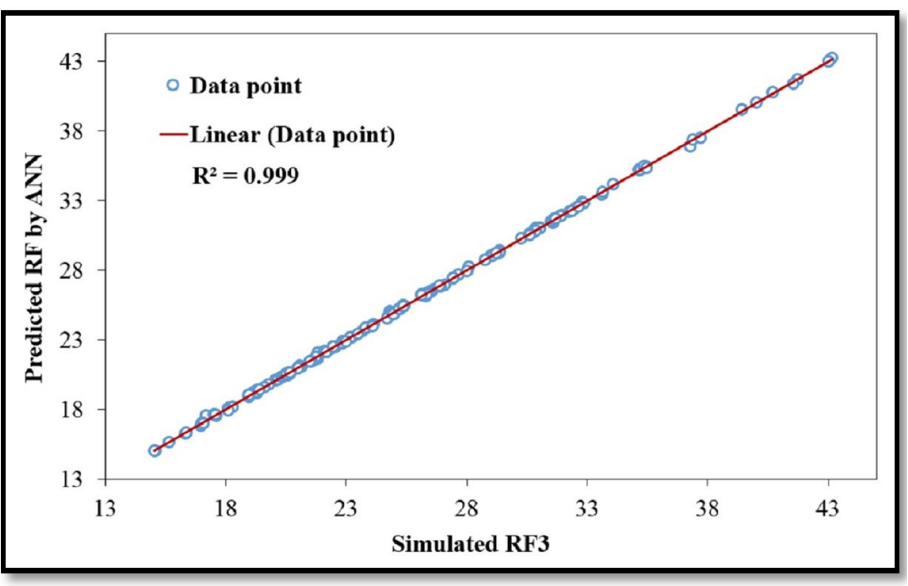

(c)

Figure 5. Correlation of recovery factor $(\mathrm{RF})$ values between the simulated data and ANN prediction for (a) $\mathrm{RF}_{1}$, (b) $\mathrm{RF}_{2}$, and (c) $\mathrm{RF}_{3}$.

To train the ANN model, the Levenberg-Marquardt back-propagation algorithm was associated with the 10 neurons in the hidden layer. This combination led to a good prediction, giving an RMSE value of $<1 \%(0.31 \%)$ during the validation test. In addition, the results obtained from validating the data confirmed what was learned in the training process. The $\mathrm{R}^{2}$ values governing the output prediction obtained during the validation of the trained model were 0.999. Figures A1-A4 illustrate the simulated data against the predicted data for the validating and testing process along with a graphical representation of the correlation. Table 5 lists a comparison of the validating results of $\mathrm{RF}_{1}$, $\mathrm{RF}_{2}$, and $\mathrm{RF}_{3}$ obtained from the ANN model with multiple linear regression (MLR).

Table 5. Comparison of ANN results versus multiple linear regression (MLR).

\begin{tabular}{cccc}
\hline Output & Method & $\mathbf{R}^{\mathbf{2}}$ & RMSE \\
\hline \multirow{2}{*}{$\mathrm{RF}_{1}$} & ANN & 0.999 & 0.11 \\
\cline { 2 - 4 } & MLR & 0.993 & 2.37 \\
\hline \multirow{2}{*}{$\mathrm{RF}_{2}$} & ANN & 0.999 & 0.37 \\
\cline { 2 - 4 } & MLR & 0.929 & 6.24 \\
\hline \multirow{2}{*}{$\mathrm{RF}_{3}$} & ANN & 0.999 & 0.36 \\
\cline { 2 - 4 } & MLR & 0.959 & 4.58 \\
\hline
\end{tabular}

Comparing the results with other methods was very important for examining the reliability of our modeled ANN predictions against those obtained from smooth techniques before testing the whole model. Multiple linear regression (MLR) was chosen to compare the results obtained using ANN because unlike ANN, which has prediction calculations based on the nonlinearity of variables, MLR uses a linear relationship between input variables and objectives. The determination of the results of $R^{2}$ and RMSE was made possible by using the function denoted in Figure 6 under the MATLAB environment.

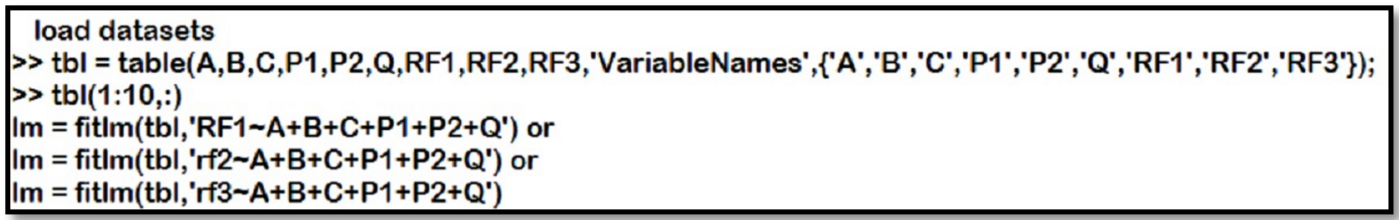

Figure 6. Function used under MATLAB environment to proceed with MLR prediction. 
It was clearly be discerned that $\mathrm{R}^{2}$ and RMSE are different. The prediction results obtained from MLR for $\mathrm{RF}_{1}$ were exceptional, demonstrating great accuracy for the prediction model. Although the result of the correlation obtained from MLR for $\mathrm{RF}_{1}$ was expectations with $\mathrm{R}^{2}=0.993$ and $\mathrm{RMSE}=2.37 \%$, while the ANN R ${ }^{2}$ and RMSE for $\mathrm{RF}_{1}$ were 0.999 and $0.11 \%$, respectively, the ANN model still obtained better results for $\mathrm{RF}_{2}$ and $\mathrm{RF}_{3}$ ( 0.999 and 0.999 , respectively) compared to MLR. This was also supported by the RMSE results. The MLR model gave RMSE results for $\mathrm{RF}_{2}$ and $\mathrm{RF}_{3}$ that were higher than those of the ANN (6.24\% and $4.58 \%$, respectively), but they were not better because they are not as close to zero as the model resulting from the ANN. Therefore, the prediction made by using the ANN was more precise.

Based on these results, we conclude that the predicted data precisely followed the simulated data with almost perfect accuracy. The same architecture applied for the validating process was extended to the testing process. The $\mathrm{R}^{2}$ value of the parameters was 0.999 .

Table 6 presents $\mathrm{R}^{2}$ and RMSE values for the different processes, including the overall dataset, while Figure 7 illustrates the correlation for the overall processes.

Table 6. Performance of ANN modeling in all processes.

\begin{tabular}{ccccc}
\hline Type of Data Set & Measures & $\mathbf{R F}_{\mathbf{1}}$ & $\mathbf{R F}_{\mathbf{2}}$ & $\mathbf{R F}_{\mathbf{3}}$ \\
\hline \multirow{2}{*}{ Training Set } & $\mathrm{R}^{2}$ & 0.999 & 0.999 & 0.999 \\
& $\mathrm{RMSE}$ & 0.001 & 0.003 & 0.002 \\
\hline \multirow{2}{*}{ Validation Set } & $\mathrm{R}^{2}$ & 0.999 & 0.999 & 0.999 \\
& $\mathrm{RMSE}$ & 0.001 & 0.003 & 0.004 \\
\hline \multirow{2}{*}{ Testing Set } & $\mathrm{R}^{2}$ & 0.999 & 0.999 & 0.999 \\
& $\mathrm{RMSE}$ & 0.001 & 0.004 & 0.003 \\
\hline \multirow{2}{*}{ Overall } & $\mathrm{R}^{2}$ & 0.999 & 0.999 & 0.999 \\
& $\mathrm{RMSE}$ & 0.001 & 0.003 & 0.003 \\
\hline
\end{tabular}
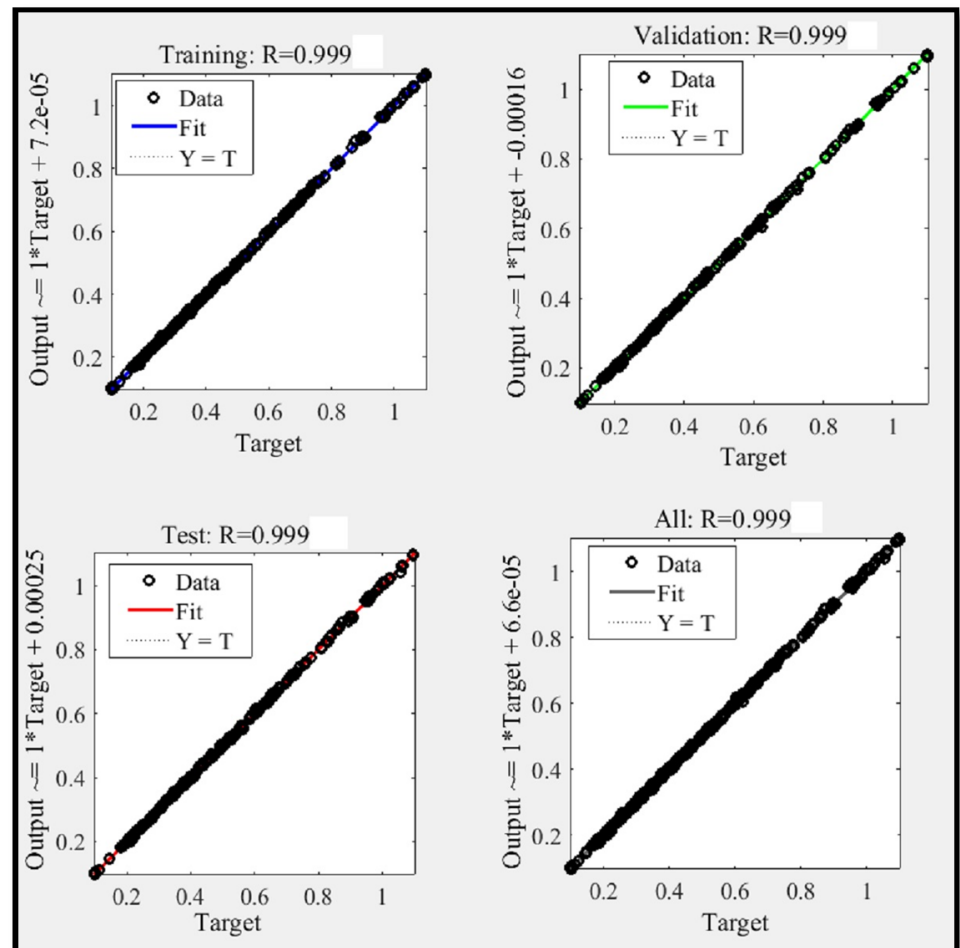

Figure 7. Correlation of the overall processes (training, validating, and testing) for the recovery factor. 
Although the ANN model had never been used on the validation and testing dataset, it was able to give precise and accurate prediction for the recovery factor. Thus, the dataset used during the training step was new. During the validation and testing processes, the errors were $<1 \%$. It was more than acceptable to have such an error range to authenticate the capability of the ANN for modeling two-slug polymer flooding.

A sensitivity analysis to determine the most significant parameters influencing the two-slug polymer flooding was performed on the input parameters. This analysis was conducted in two steps, first by taking only a single parameter into consideration, and then by taking two parameters into consideration.

In the first set, there were six factors investigated for $\mathrm{RF}_{2}$ and $\mathrm{RF}_{3}$, as depicted in the Pareto chart (Figure 8).

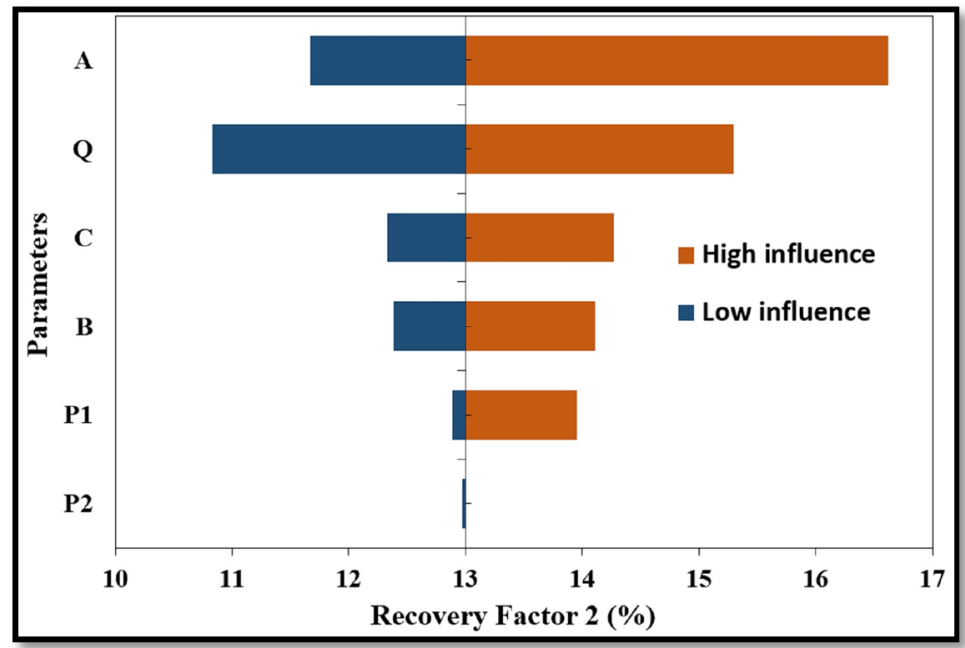

Figure 8. Results of sensitivity analysis of single parameters on the effect on recovery factor $2\left(\mathrm{RF}_{2}\right)$.

For $\mathrm{RF}_{2}$, the chart clearly indicates that the polymer slug 1 size $(\mathrm{A})$ and the injection rate $(\mathrm{Q})$ made important contributions to the fluctuation of $\mathrm{RF}_{2}$, with a contribution of $>15 \%$, while the remaining four parameters were below that range. Polymer slug size $2(\mathrm{C})$, the water drive (B), and the concentration of polymer slug size $1\left(\mathrm{P}_{1}\right)$ showed poor performances. The concentration of polymer slug size 2 $\left(\mathrm{P}_{2}\right)$, however, made no significant contribution to $\mathrm{RF}_{2}$, which could be explained by the fact that $\mathrm{RF}_{2}$ corresponded to the period of applicability of the first polymer concentration while $\mathrm{P}_{2}$ represented the concentration of the second polymer. Based on that, the interaction effects of $A Q$ versus $R_{2}$, and $A P_{1}$ versus $R_{2}$ were investigated, even though $P_{1}$ 's contribution was judged to be poor. Figure 9 a shows the interaction between polymer slug 1 size and injection rate. As can be seen, larger polymer slugs and higher injection rates yielded better recovery factors. In addition, even though it was not directly noticeable, the injection rate played a key role in the amelioration of final recovery. The interaction between $A$ and $P_{1}$ was also investigated, as depicted in Figure $9 \mathrm{~b}$. For periods of $<20$ months, the figure showed that the interaction was not effective, but starting when the slug size was $>20$ months, a good recovery factor was reached when both parameters were at their maxima. This clearly indicates that the effectiveness of the polymer concentration is linked with the size of the slug. A small slug size would bring poor results, even with effective design of the polymer concentration. 


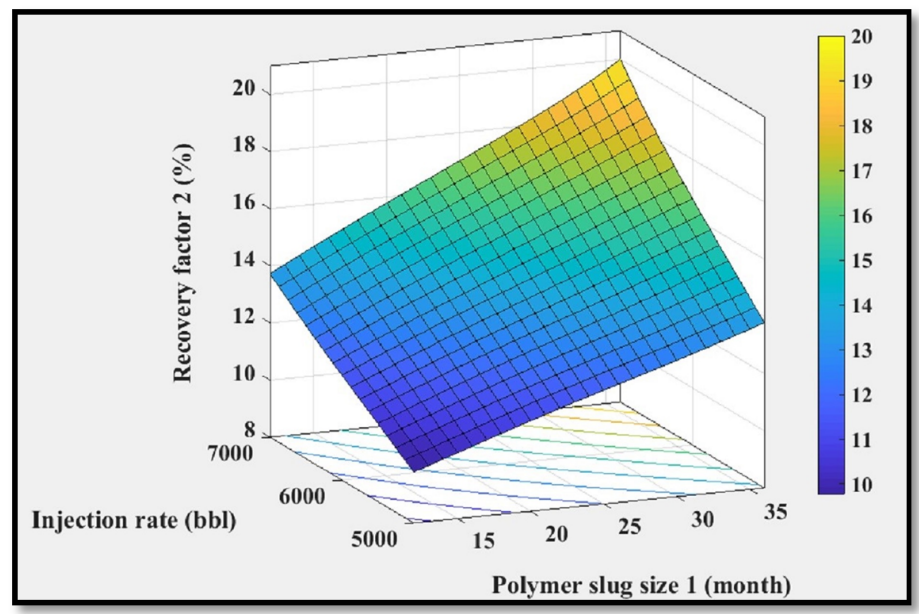

(a)

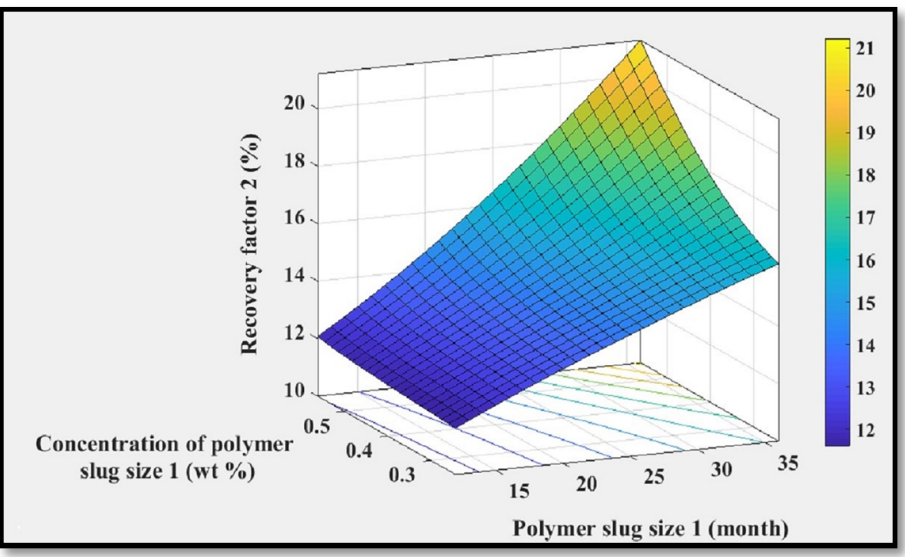

(b)

Figure 9. Description of the interactive effect of (a) polymer slug 1 size and injection rate on $\mathrm{RF}_{2}$, and (b) polymer slug 1 size and polymer slug 1 concentration on $\mathrm{RF}_{2}$.

A summary of the Pareto chart showing the significance of parameters on $\mathrm{RF}_{3}$ is depicted in Figure 10.

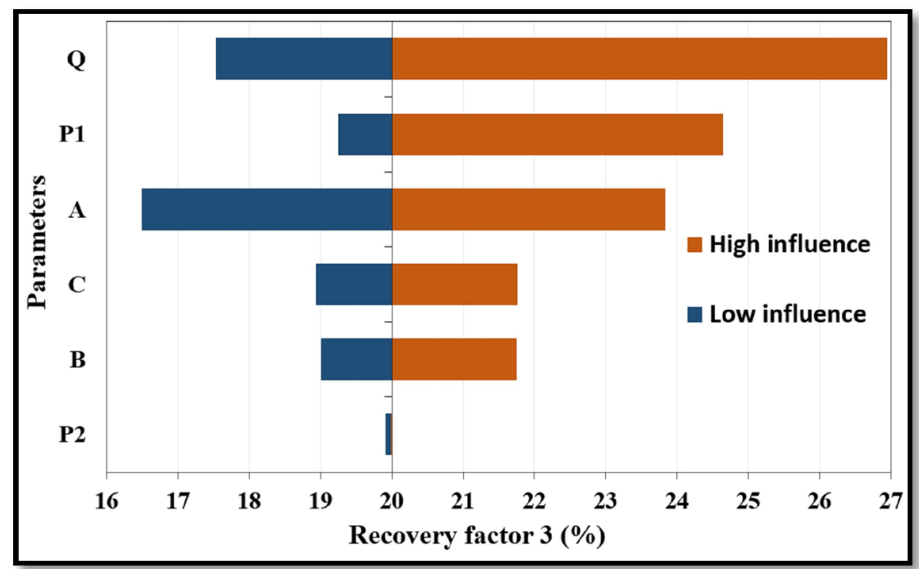

Figure 10. Results of the sensitivity analysis of single parameters of the effect on $\mathrm{RF}_{3}$. 
Primarily, attention was given to parameters showing a contribution of $>23 \%$. Among these, $Q$, $\mathrm{P}_{1}$, and A were judged in order of significance to fulfill this criterion. $\mathrm{P}_{2}$ in this case did perform poorly while $C$ and $B$ gave good results, but this was below the limitation range. The poor performance of $P_{2}$ can be linked to the reduction of permeability after the injection of $\mathrm{P}_{1}$. Basically, injecting polymer to recover more oil changed the permeability of the reservoir. If the concentration of the injected polymer is high, the permeability of the reservoir will be reduced, lowering the efficiency of a second polymer if it would be injected. To tackle this, a slightly high polymer viscosity compared to the oil's viscosity should be chosen for the first polymer slug to allow the second polymer slug to also be effective. Plots of $A P_{1}$ versus $R F_{3}$ and $A Q$ versus $R F_{3}$ (Figure 11) showed appreciable rises in recovery factor $(>30 \%)$, indicating a strong interaction between these parameters.

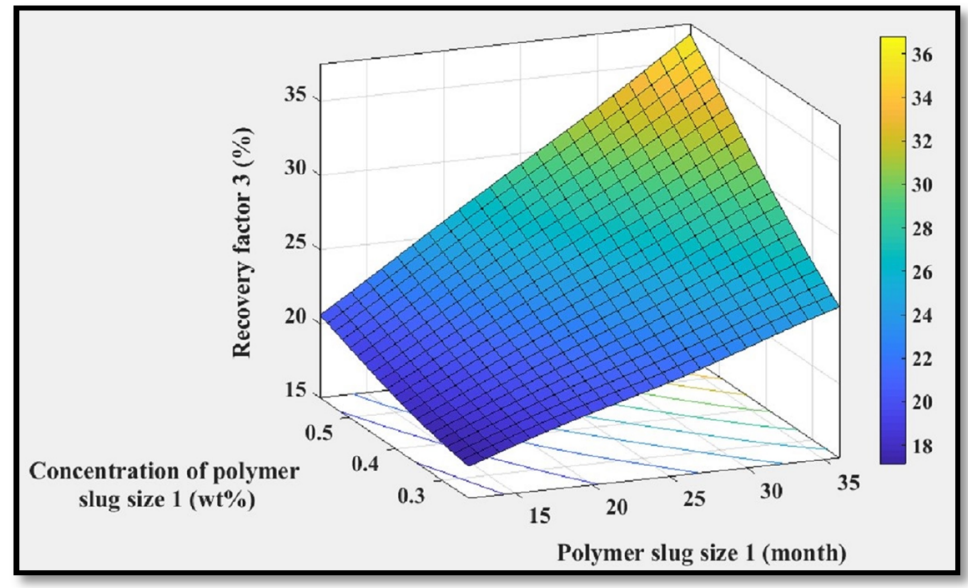

(a)

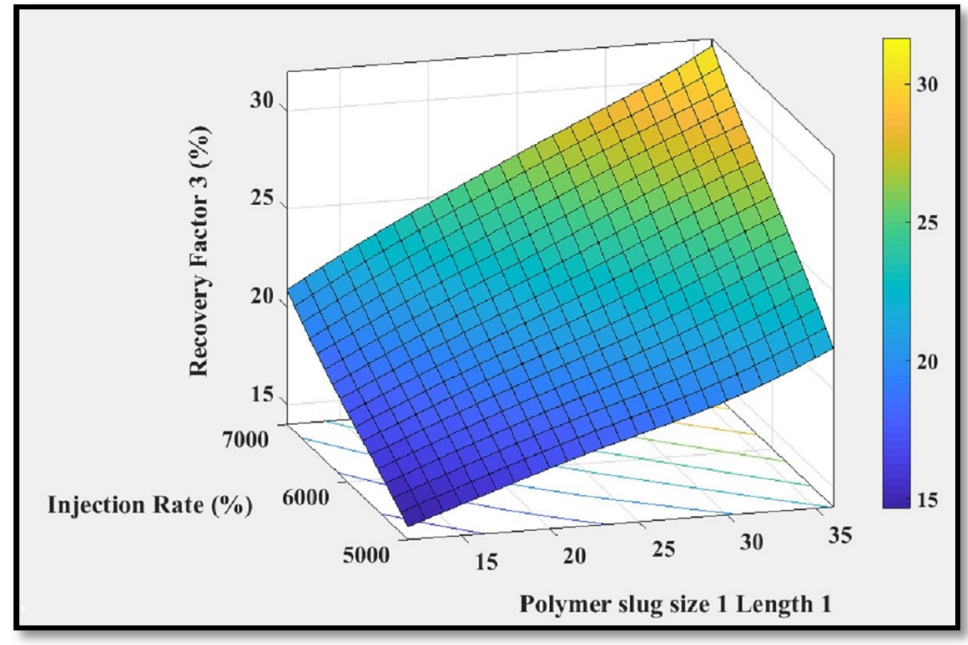

(b)

Figure 11. Description of the interactive effect of (a) polymer slug 1 size and the polymer slug 1 concentration on $\mathrm{RF}_{3}$ and (b) polymer slug 1 size and the injection rate on $\mathrm{RF}_{3}$.

Other parameters supposed to influence $\mathrm{RF}_{3}$ were $\mathrm{C}$ and $\mathrm{P}_{2}$. It was noticeable that their contributions to $\mathrm{RF}_{3}$ were $>26 \%$. Coupling AC showed that, to lead to better results, both slugs 1 and 2 must either be injected for a longer period or, if $C$ is not large, A must be large, or vice versa. $\mathrm{CP}_{1}$, however, showed a contribution of up to $26 \%$ and a good interaction between $\mathrm{C}$ and $\mathrm{P}_{1}$, showing significant changes when the parameters were higher. Figure 12 shows a summary of the coupled parameter results. 


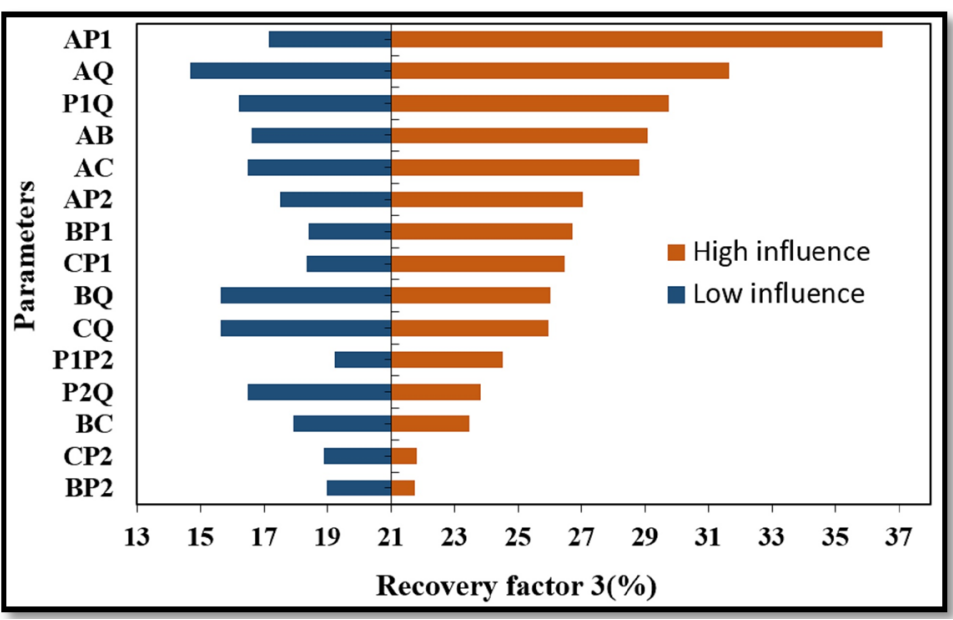

Figure 12. Summary of the results of the sensitivity analysis of coupled parameters on $\mathrm{RF}_{3}$ showing the significance of each variable.

The parameters highlighted during the sensitivity analysis can then be optimized to lead to better results than those obtained during this study to minimize costs if the net present value is considered.

\section{Conclusions}

A simulation study and artificial neural network modeling of polymer flooding composed of two polymers slugs were performed to predict the recovery factor at three distinct periods $\left(R_{1}\right.$, $\mathrm{RF}_{2}$, and $\mathrm{RF}_{3}$ ) in which the input data were polymer slug size $1(\mathrm{~A})$, water drive (B), polymer slug size $2(\mathrm{C})$, concentration of polymer slug size $1\left(\mathrm{P}_{1}\right)$, concentration of polymer slug size $2\left(\mathrm{P}_{2}\right)$, and injection rate $(\mathrm{Q})$. The modeling of the ANN algorithm was divided into three processes-training, validating, and testing - with data allocated to each in the ratios of 45:20:35. To reach accurate results, the data were normalized to be in the same range between 0.1 and 1.1. The overall correlations for the training, validating, and testing processes between the simulated results and the ANN predictions were 0.999 . RMSE values were also reported to be $0.11 \%, 0.37 \%$, and $0.36 \%$ for the recovery factor at the three distinct times. During the validation process, the results obtained from the ANN model were compared to those from MLR. This comparison showed that the ANN had better performance, and this was confirmed by test results in which the prediction followed with high accuracy compared to the simulated results. To conclude, a sensitivity analysis was completed to gain a better understanding of the parameters influencing the recovery factor. A first sensitivity analysis was conducted on single parameters and another analysis on coupled parameters. The results clearly showed that the injection rate and concentration of polymer slug size 1 and polymer slug size 2 , and water drive size were the most significant parameters. However, the concentration of polymer slug size 2 did not play a key role in this process. This was confirmed in the MLR prediction, showing a $p$ value $>0.005$. However, polymer slug size 2 had a major impact in the final recovery factor. The sensitivity study on coupled parameters showed that the coupled parameters with the most influence were in the following order of importance: $\mathrm{AP}_{1}, \mathrm{AQ}, \mathrm{P}_{1} \mathrm{Q}, \mathrm{AB}, \mathrm{AC}, \mathrm{AP}_{2}, \mathrm{BP}_{2}$, and $\mathrm{CP}_{1}$. Other coupled parameters not present in this list showed a final recovery factory of $<26 \%$. This study showed the capability of the proposed ANN model for predicting the recovery factor in polymer flooding with two polymers slugs with good accuracy.

Author Contributions: All authors have worked on this manuscript together and all authors have read and approved the final manuscript.

Conflicts of Interest: The authors declare no conflict of interest. 


\section{Appendix A}

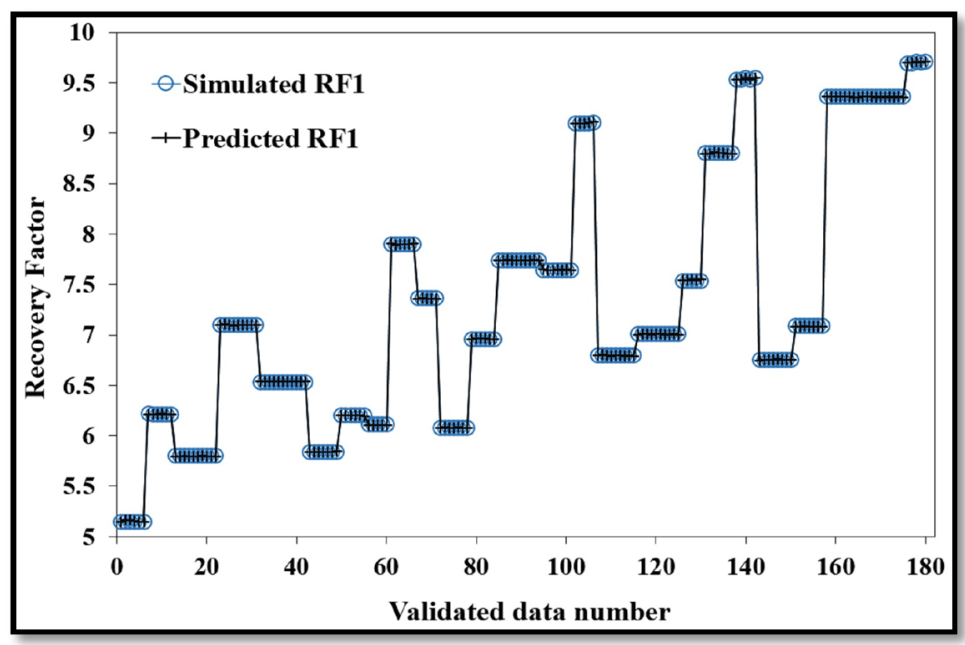

(a)

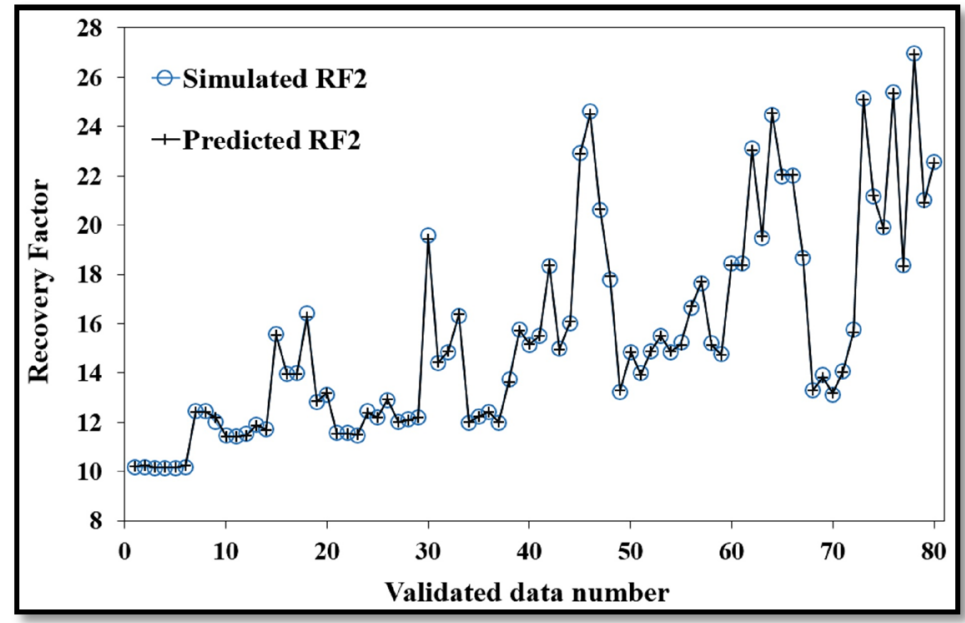

(b)

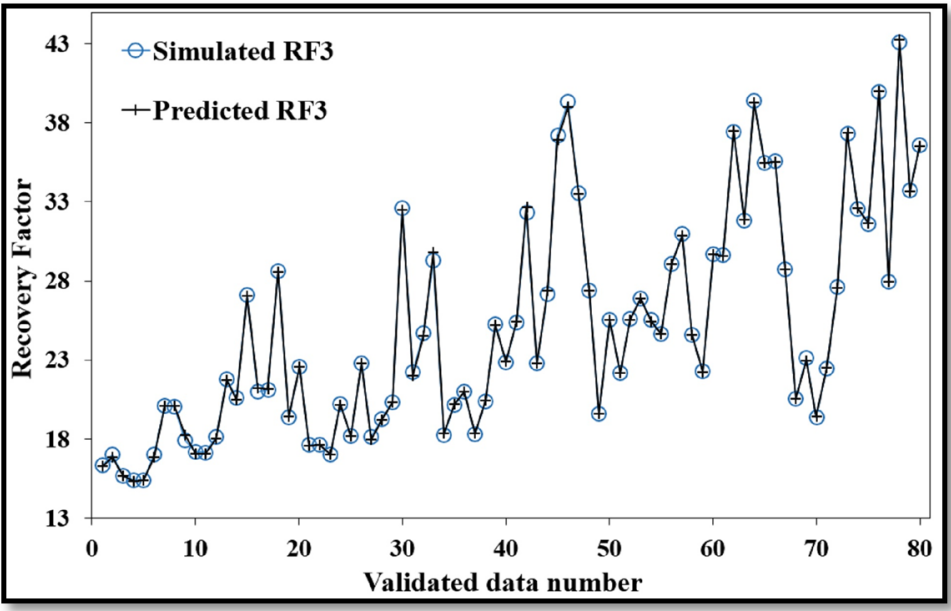

(c)

Figure A1. Illustration of the simulated data against the predicted data during the validating process for (a) $\mathrm{RF}_{1},(\mathbf{b}) \mathrm{RF}_{2}$, and (c) $\mathrm{RF}_{3}$. 


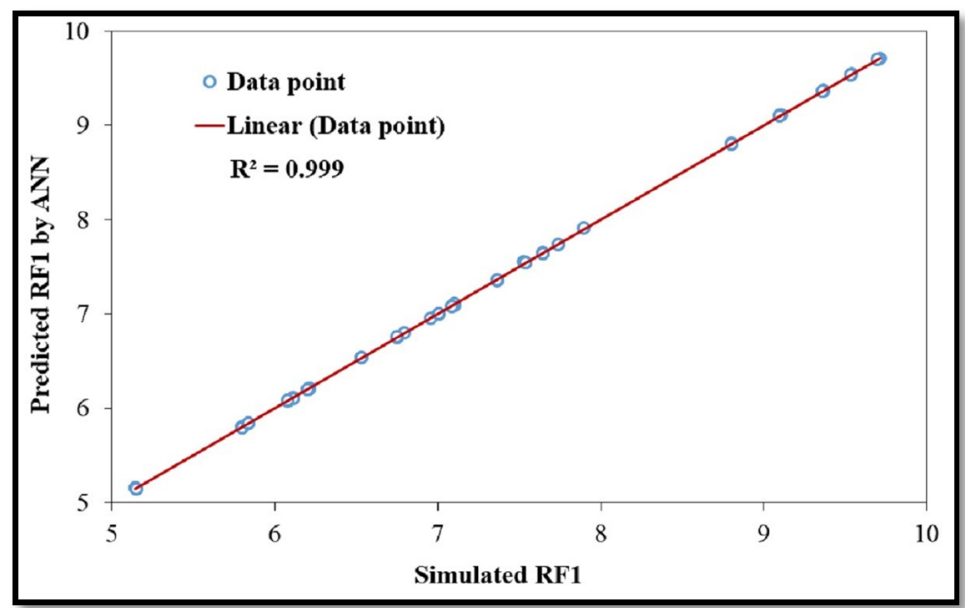

(a)

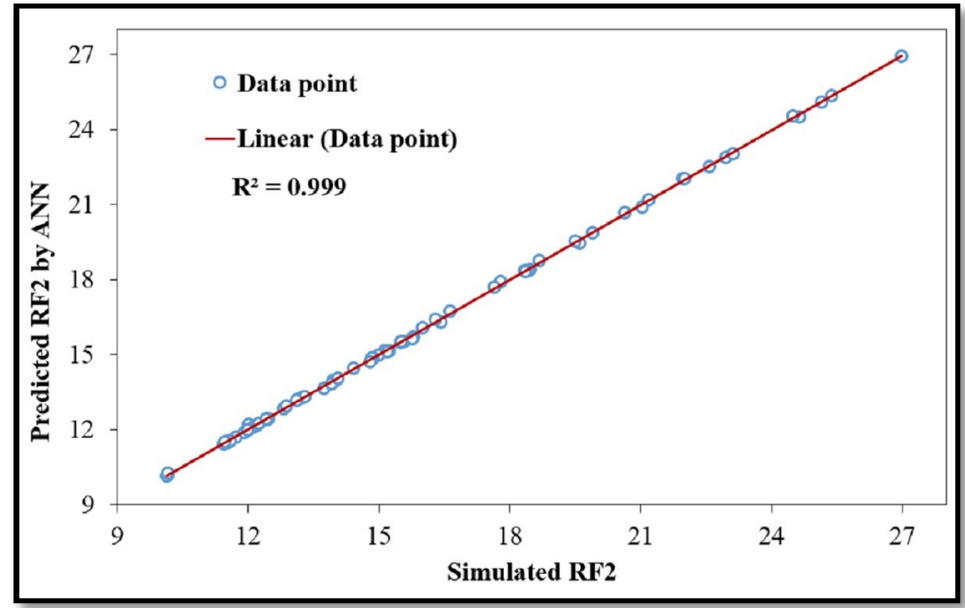

(b)

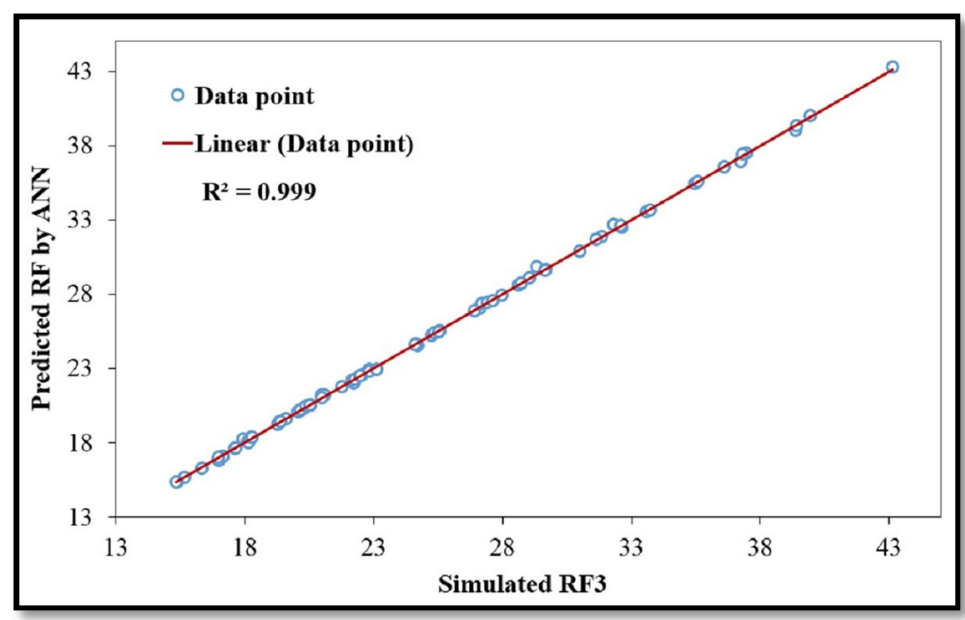

(c)

Figure A2. Illustration of the correlation coefficient for predicted data against the simulated data during the validating process for (a) $\mathrm{RF}_{1},(\mathbf{b}) \mathrm{RF}_{2}$, and (c) $\mathrm{RF}_{3}$. 


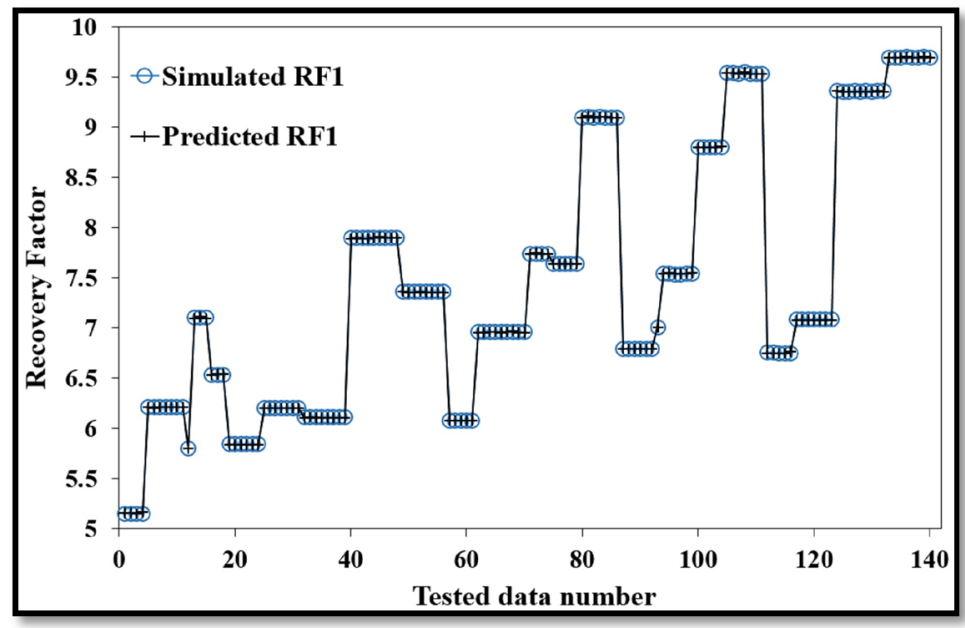

(a)

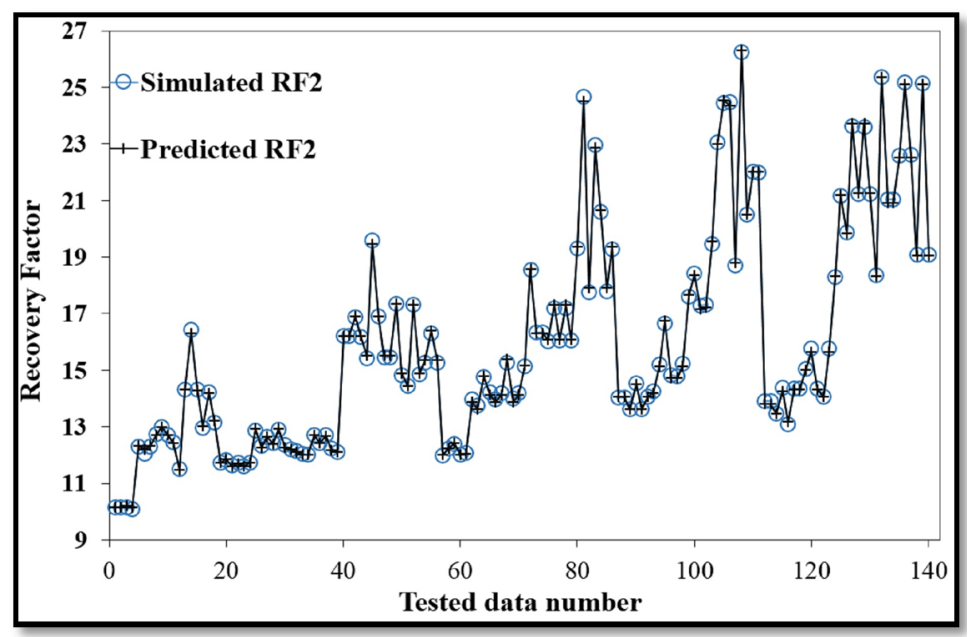

(b)

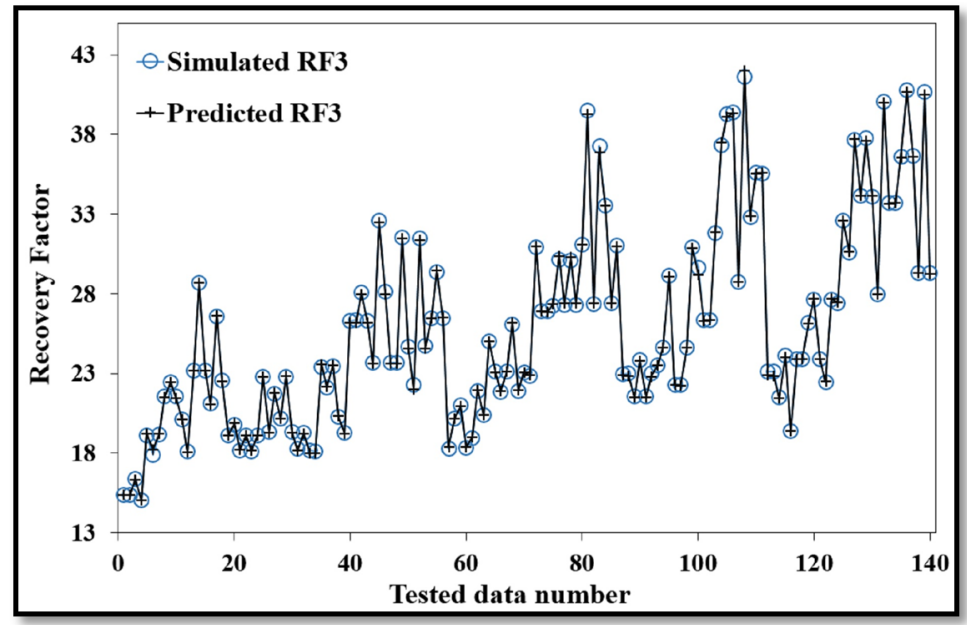

(c)

Figure A3. Illustration of the simulated data against the predicted data during the testing process for (a) $\mathrm{RF}_{1}$, (b) $\mathrm{RF}_{2}$, and (c) $\mathrm{RF}_{3}$. 


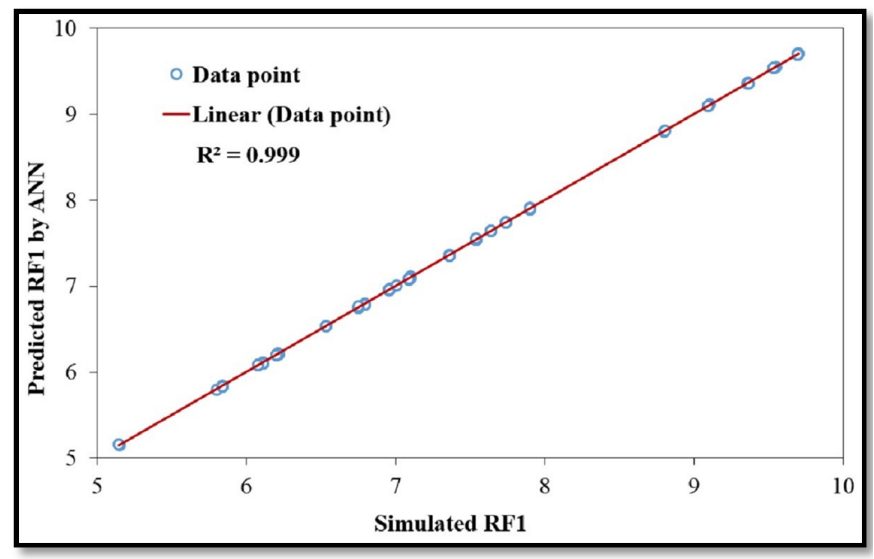

(a)

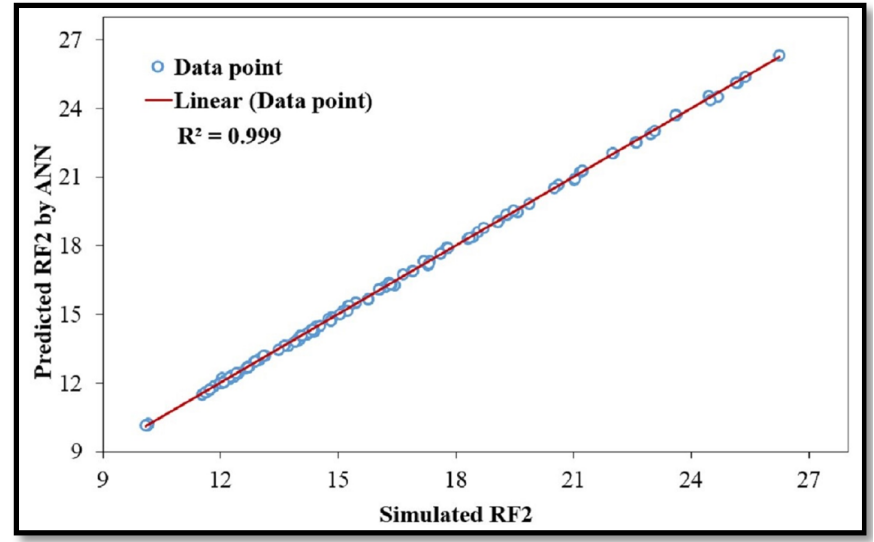

(b)

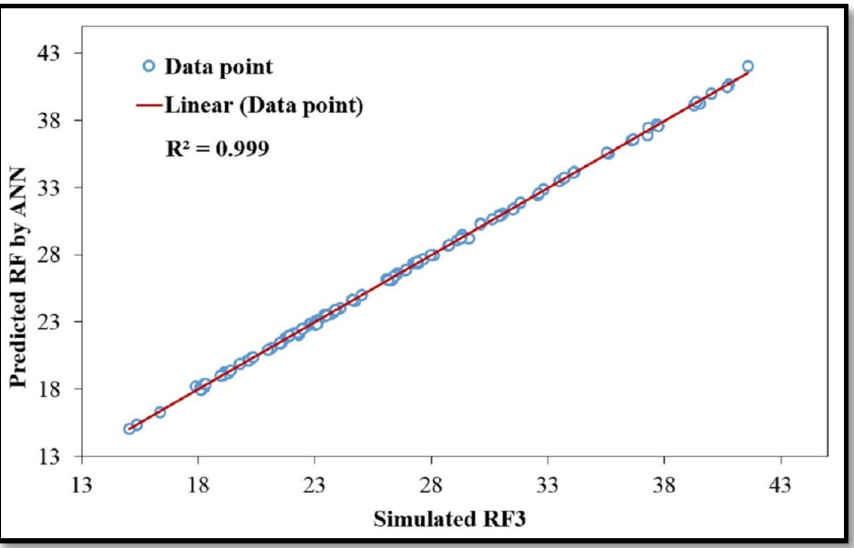

(c)

Figure A4. Illustration of the correlation coefficient for the predicted data against the simulated data during the testing process for (a) $\mathrm{RF}_{1}$, (b) $\mathrm{RF}_{2}$, and (c) $\mathrm{RF}_{3}$.

\section{References}

1. Lake, L.W.; Schmidt, R.L.; Venuto, P.B. A niche for enhanced oil recovery in the 1990s. Oilfield Rev. 1992, 3, 55-61.

2. Ahmadi, M.A.; Pournik, N. A predictive model of chemical flooding for enhanced oil recovery purposes: Application of least square support vector. Petroleum 2015, 2, 177-182. [CrossRef]

3. Si, L.V.; Chon, B.H. Well-pattern investigation and selection by surfactant-polymer flooding performance in heterogenous reservoir consisted of interbedded low-permeability layer. Korean J. Chem. Eng. 2016, 33, 3456-3464. 
4. Benzagouta, M.S.; AlNashef, I.M.; Karmanda, W.; Al-Khidir, K. Ionic liquids as novel surfactants for potential use in enhanced oil recovery. Korean J. Chem. Eng. 2013, 30, 2108-2117. [CrossRef]

5. Abidin, A.Z.; Puspasari, T.; Nugroho, W.A. Polymers for enhanced oil recovery technology. Proc. Chem. 2012, 4, 11-16. [CrossRef]

6. Sheng, J.J.; Leonhardt, B.; Azri, N. Status of polymer-flooding technology. J. Can. Pet. Technol. 2015, 54, 116-126. [CrossRef]

7. Alsofi, A.M.; Blunt, M.J. Polymer flooding design and optimization under economic uncertainty. J. Pet. Sci. Eng. 2014, 124, 46-59. [CrossRef]

8. Hou, J.; Li, Z.-Q.; Cao, H.-L.; Song, X.-W. Integrating genetic algorithm and support vector machine for polymer flooding production performance prediction. J. Pet. Sci. Eng. 2009, 68, 29-39. [CrossRef]

9. Bang, H.W.; Caudle, B.H. Modeling of a micellar/polymer process. SPEJ 1984, 24, 617-627. [CrossRef]

10. Bondor, P.L.; Hirasaki, G.J.; Tham, M.J. Mathematical simulation of polymer flooding in complex reservoirs. SPEJ 1972, 12, 369-382. [CrossRef]

11. Pope, G.A.; Nelson, R.C. A chemical flooding compositional simulator. SPEJ 1978, 18, 339-354. [CrossRef]

12. Paul, G.W.; Lake, L.W.; Pope, G.A.; Young, G.B. A simplified predictive model for micellar-polymer flooding. In Proceedings of the SPE California Regional Meeting, San Francisco, CA, USA, 24-26 March 1982.

13. Pope, G.A. The application of fractional flow theory to enhanced oil recovery. SPEJ 1980, 20, 191-205. [CrossRef]

14. Daripa, P.; Glimm, J.; Lindquist, B.; McBryan, O. Polymer floods: A case study of nonlinear wave analysis and of instability control in tertiary oil recovery. J. Appl. Math. 1988, 48, 353-373. [CrossRef]

15. Daripa, P.; Dutta, S. Modeling and simulation of surfactant-polymer flooding using a new hybrid method. J. Comput. Phys. 2017, 335, 249-282. [CrossRef]

16. Masoudi, P.; Arbab, B.; Mohammadrezai, H. Net pay determination by artificial neural network: Case study on Iranian offshore oil fields. J. Pet. Sci. Eng. 2014, 123, 72-77. [CrossRef]

17. Al-Bulushi, N.I.; King, P.R.; Blunt, M.J.; Kraaijveld, M. Artificial neural networks workflow and its application in the petroleum industry. Neural Comput. Appl. 2010, 21, 409-421. [CrossRef]

18. Chakra, N.C.; Song, K.Y.; Gupta, M.M.; Saraf, D.N. An innovative neural forecast of cumulative oil production from a petroleum reservoir employing higher-order neural networks (HONNs). J. Pet. Sci. Eng. 2013, 106, 18-33. [CrossRef]

19. Mohammadi, M.; Kouhi, M.; Mohebbi, A. Prediction of oil recovery factor in $\mathrm{CO}_{2}$ injection process. Pet. Sci. Tech. 2014, 2, 2093-2101. [CrossRef]

20. Kang, P.S.; Lim, J.-S.; Chun, H. Artificial neural network model to estimate the viscosity of polymer solutions for enhanced oil recovery. Appl. Sci. 2016, 6, 188. [CrossRef]

21. Al-Dousari, M.M.; Garrouch, A.A. An artificial neural network model for predicting the recovery performance of surfactant polymer floods. J. Pet. Sci. Eng. 2013, 109, 51-62. [CrossRef]

22. Saboorian-Jooybari, H.; Dejam, M.; Chen, Z. Heavy oil polymer flooding from laboratory core floods to pilot tests and field applications: Half-century studies. J. Pet. Sci. Eng. 2016, 142, 85-100. [CrossRef]

23. STARS User Guide; Computer Modeling Group Ltd.: Calgary, AB, Canada, 2014.

24. Janiga, D.; Czarnota, R.; Stopa, J.; Wojnarowski, P.; Kosowski, P. Performance of nature inspired optimization algorithms for polymer enhanced oil recovery process. J. Pet. Sci. Eng. 2017, 154, 354-366. [CrossRef]

25. Karambeigi, M.S.; Zabihi, R.; Hekmat, Z. Neuro-simulation modeling of chemical flooding. J. Pet. Sci. Eng. 2011, 78, 208-219. [CrossRef]

26. Ahmadloo, F.; Asghari, K.; Renouf, G. Performance prediction of waterflooding in western Canadian heavy oil reservoirs using artificial neural network. Energy Fuel 2009, 24, 2520-2526. [CrossRef]

(C) 2017 by the authors. Licensee MDPI, Basel, Switzerland. This article is an open access article distributed under the terms and conditions of the Creative Commons Attribution (CC BY) license (http:/ / creativecommons.org/licenses/by/4.0/). 